Virginis (Nature, 159, 658; 1947). He also dealt with the application of this formula to the white dwarfs and showed that in the case of Sirius B the equatorial field might be as much as $3 \times 10^{\circ}$ gauss. Such a field should lead to Paschen-Back splitting of the hydrogen lines of the order of $50 \mathrm{~A}$., and Thackeray gives a full description of his work with the 36-inch Common reflector at the Solar Physics Observatory, Cambridge, to detect this effect. Unfortunately, there is not a very wide choice of white dwarfs suitable for the experiment, and Wolf 1346, magnitude $11 \cdot 3$, was selected as it was attainable with a 1-prism slitless spectrograph attached to the 36-in. reflector. It was shown that Paschen-Back splitting of $H \gamma$ is unlikely to exceed $8 \mathrm{~A}$. in this star, corresponding to an upper limit of $10^{\circ}$ gauss. It is emphasized that there is need for greater spectral purity in a discussion of an apparent structure in the lines, which is independent of the polarizing analyser. When 40 Erid. B became accessible in September 1947 a 2-in. $f / 1$ aspherical singlet, figured and lent by Dr. C. R. Burch, was attached to the Newall 25-in. refractor for an attempt with the Wood aluminized grating spectrograph. An hour's exposure without 'Polaroid' was obtained on September 25, showing $H \gamma$ only, but exposures of one hour on September 25 and $3 \frac{1}{2}$ hours on September 27 through the analyser failed owing to the formation of thick haze during exposure.

\section{Recession of Glaciers}

THE Royal Geographical Society has inaugurated its new Research Series with a paper by Prof. $H$. W. Ahlmann on glaciological research on the North Atlantic coasts (London: Royal Geographical Society, 1948. 7s. 6d.). Prof. Ahlmann puts together his own and other observations on glaciers in Norway, Iceland, East Greenland and Spitsbergen. All data point the same way, to a general recession, and the same is true in many other parts of the world. The present rapid shrinkage seems to be the last stage in a recession that began about two hundred years ago when the glaciers reached their maximum extension in historical, and perhaps in post-glacial, times. This recession has resulted too in a rise of sea-level, as noted by J. Thorarinsson, F. Bergsten and others. The increasing intensity of the recession is also shown by recent changes in the extension of the Arctic packice, notably in the Russian Arctic and around Spitsbergen, the northward migration of fish and certain birds and the improved cereal prospects in Iceland. The phenomenon is so widespread that it would appear to be associated with climatic fluctuations. The chief meteorological cause is held to be due to increased ablation. Radiation plays a part; but conduction. is more important in the smaller icefields and at lower altitudes. On the other hand, it is stated that in the high interior of the Greenland ice there has been no increased ablation or reduced thickness of the ice. The low-pressure area of the North Atlantic apparently has moved to the north in recent years, thus favouring the flow of warm air to the Arctic.

\section{Gresham's School Natural History Society}

THE twenty-sixth report of Gresham's School Natural History Society (1948) has just been received. Membership of the Society totals well over a hundred $\longrightarrow$ an eminently satisfactory number for a school. The Society is divided into Archæological, Astronomical, Botanical, Entomological, Meteorological and Ornithological Sections, all of which carry out valuable field work and present reports and papers to the Society. In the present report there are : (1) a survey of the flora of Holt and district, with an exhaustive list of plants observed ; (2) an account of the surrounding insect fauna, together with lists of Lepidoptera and Orthoptera ; (3) a descriptive account of the birds of the area, with a very comprehensive list and a detailed study of a fulmar colony. Extracts of papers submitted for the Holland-Martin Natural History Prizes (1944-47) are appended. The boys of Gresham's School are to be congratulated on their efficient and very valuable Natural History Society, which obviously encourages practical and field work to the utmost-a fitting basis for later work in natural history, and a great asset in their general education.

\section{Dr. Franz Weidenreich on Human Evolution}

A NUMBER of interesting papers by Dr. Franz Weidenreich are to hand. "The Trend of Human Evolution" is published in Evolution (1, No. 4; Dec., 1947), and "Some particulars of skull and brain of early hominids and their bearing on the problem of the relationship between Man and the Anthropoids" appears in the American Journal of Physical Anthropology, 5 (N.S.), No. 4 (Dec., 1947). In an article in the American Anthropologist, 45, No. 1 (Jan.-March, 1943), Dr. Weidenreich once again affirms his belief that Neanderthal man was the ancestor of Homo sapiens. The majority of physical anthropologists will probably not agree with the theories set forth in "The Neanderthal Man and the ancestors of Homo sapiens", but nevertheless Dr. Weidenreich can never be igmored with impunity. The last article comes from the Transactions of the New York Academy of Sciences, Series II, 4, No. 1 (Nov., 1941). It is a lecture on the site and technique of excavation of fossil man in Choukoutien, China. No anatomical details of the finds are given; but the student will find conveniently set out the story of the discovery and the excavation.

\section{The Sondes Place Research Institute}

THE Sondes Place Research Institute, Dorking, Surrey, of MacTaggart and Evans, Ltd., industrial consultants, is described briefly in an illustrated booklet which this firm has issued. There are fifteen laboratories, besides offices, stores, dark room, library and semi-scale building and workshops. The Analytical Laboratory and the Physical Testing and Cement Laboratories are service laboratories carrying out analysis and testing for the rest of the organisation and to some extent for elients. The Spectroscopy and Microscopy Laboratories and the dark room, as well as the $\mathrm{X}$-ray Analysis Laboratory, function both as service departments and as research laboratories, but the main chemical laboratory is used exclusively for research and development. The Physical Laboratory is used mainly for physico-chemical research and for determining physical constants, while the Electronics Laboratory deals with the application of electronic methods and servo-mechanisms to industry. Work is carried out either for a fixed fee, on a time basis, or for a monthly or yearly retainer; during the past few years problems relating to abrasives, adhesives, bricks, cast iron, cement and concrete, detergents, fibre boards, gelatine and glue, gypsum, lime, linoleum substitute, mineral oils, paint, plasties, printing, synthetic organic chemicals, strip steel, etc., have been handled. 